\title{
SPECTRAL OPTIMIZATION FOR SINGULAR SCHRÖDINGER OPERATORS
}

\author{
PAVEL EXNER
}

Abstract. For several classes of singular Schrödinger operators which can be formally written as $-\Delta-\alpha \delta(x-\Gamma)$ we discuss the problem of optimization of their principal eigenvalue with respect to the shape of the interaction support $\Gamma$.

Mathematics subject classification (2010): 81Q35, 35J10, 35P15.

Keywords and phrases: Singular Schrödinger operators, principal eigenvalue, shape optimization.

\section{REFERENCES}

[1] A. Abrams, J. Cantarella, J.G. Fua, M. Ghomi, R. Howard, Circles minimize most knot energies, Topology 42 (2003), 381-394.

[2] S. Albeverio, F. Gesztesy, R. Høegh-Krohn, H. Holden, Solvable Models in Quantum Mechanics, second edition, Amer. Math. Soc., Providence, R.I., 2005.

[3] J.-P. Antoine, F. GesZTESY, J. ShABANi, Exactly solvable models of sphere interactions in quantum mechanics, J. Phys. A: Math. Gen. 20 (1987), 3687-3712.

[4] P. Antunes, P. Freitas, D. KREJČIŘíK, Bounds and extremal domains for Robin eigenvalues with negative boundary parameter, Adv. Calc. Var. 10 (2017), 357-380.

[5] M.S. Ashbaugh, R.D. Benguria, Proof of the Payne-Pólya-Weinberger conjecture, Bull. Am. Math Soc. 25 (1991), 19-29.

[6] M.S. Ashbaugh, R.D. Benguria, A second proof of the Payne-Pólya-Weinberger conjecture, Commun. Math. Phys. 147 (1992), 181-190.

[7] E. Bannai, E. BANNAI, A survey on spherical designs and algebraic combinatorics on spheres, Eur. J. Combin. 30 (2009), 1392-1425.

[8] M. BAREKET, On an isoperimetric inequality for the first eigenvalue of a boundary value problem, SIAM J. Math. Anal. 8 (1977), 280-287.

[9] J. Behrndt, P. EXNER, V. LOTOREICHIK, Schrödinger operators with $\delta$ and $\delta^{\prime}$-interactions on Lipschitz, surfaces and chromatic numbers of associated partitions, Rev. Math. Phys. 26 (2014), 1450015.

[10] R.D. Benguria, H. Linde, B. Loewe, Isoperimetric inequalities for eigenvalues of the Laplacian and the Schrödinger operator, Bull. Math. Sci. 2 (2012), 1-56.

[11] G. Berkolaiko, P. Kuchment, Introduction to Quantum Graphs, Amer. Math. Soc., Providence, R.I., 2013.

[12] J.F. BRASCHE, P. EXNER, YU.A. KUPERIN, P. ŠEBA, Schrödinger operators with singular interactions, J. Math. Anal. Appl. 184 (1994), 112-139.

[13] H. Cohen, A. Kumar, Universally optimal distribution of point on the sphere, J. Amer. Math. Soc. 20 (2007), 99-148.

[14] P. EXNER, Necklaces with interacting beads: isoperimetric problems, in Proceedings of the "International Conference on Differential Equations and Mathematical Physics" (Birmingham 2006), AMS "Contemporary Math" Series, vol. 412, Providence, R.I., 2006; pp. 141-149.

[15] P. Exner, M. FraAs, On geometric perturbations of critical Schrödinger operators with a surface interaction, J. Math. Phys. 50 (2009), 112101.

[16] P. Exner., E.M. Harrell, M. Loss, Optimal eigenvalues for some Laplacians and Schrödinger operators depending on curvature, in Proceedings of QMath7, Birkhäuser, Basel 1999; pp. 47-53. 
[17] P. EXNER, E.M. HARRELl, M. Loss, Inequalities for means of chords, with application to isoperimetric problems, Lett. Math. Phys. 75 (2006), 225-233; addendum 77 (2006), 219.

[18] P. EXner, T. ICHInose, Geometrically induced spectrum in curved leaky wires, J. Phys. A: Math. Gen. 34 (2001), 1439-1450.

[19] P. EXNER, S. KONDEJ, Curvature-induced bound states for a $\delta$ interaction supported by a curve in $\mathbb{R}^{3}$, Ann. H. Poincaré 3 (2002), 967-981.

[20] P. EXner, S. KondeJ, Ground state optimization for leaky star graphs in dimension three, Lett. Math. Phys. 110 (2020), 735-751.

[21] P. EXner, H. Kovařík, Quantum Waveguides, Springer International, Heidelberg 2015.

[22] P. ExNer, V. LotoreichiK, A spectral isoperimetric inequality for cones, Lett. Math. Phys. 107 (2017), 717-732.

[23] P. Exner, V. Lotoreichik, Optimization of the lowest eigenvalue for leaky star graphs, in Proceedings of the conference "Mathematical Results in Quantum Physics" (QMath13, Atlanta 2016; F. Bonetto, D. Borthwick, E. Harrell, M. Loss, eds.), Contemporary Math., vol 717, AMS, Providence, R.I., 2018; pp. 187-196.

[24] G. FABER, Beweis, dass unter allen homogenen Membranen von gleicher Fläche und gleicher Spannung die kreisförmige den tiefsten Grundton gibt, Sitzungsber. Bayer. Akad. Wiss. München, Math.Phys. Kl. (1923), 169-172.

[25] P. FREITAS, D. KREJČIŘíK, The first Robin eigenvalue with negative boundary parameter, Adv. Math. 280 (2015), 322-339.

[26] E.M. HARRELl, P. KRÖGER, K. Kurata, On the placement of an obstacle or a well so as to optimize the fundamental eigenvalue, SIAM J. Math. Anal. 33 (2001), 240-259.

[27] E. KRAhn, Über eine von Rayleigh formulierte Minimaleigenschaft des Kreises, Math. Ann. 94 (1925), 97-100.

[28] D. KREJČIŘíK, V. LotoreICHIK, Optimisation of the lowest Robin eigenvalue in the exterior of a compact set, J. Convex Anal. 25 (2018), 319-337.

[29] D. KREJČIŘír, V. Lotoreichik, Optimisation of the lowest Robin eigenvalue in the exterior of a compact set, II: non-convex domains and higher dimensions, Potential Anal. 52 (2020), 601-614.

[30] V. LOTOREICHIK, Spectral isoperimetric inequality for the $\delta^{\prime}$ interaction on a contour, arXiv: 1810.05457.

[31] V. LOTOREICHIK, T. OURMiÈRES-BONAFOS, On the bound states of Schrödinger operators with $\delta$-interactions on conical surfaces, Comm. PDE 41 (2016), 999-1028.

[32] G. LÜKő, On the mean length of the chords of a closed curve, Israel J. Math. 4 (1966), 23-32.

[33] J. O'HARA, Energy of knots and conformal geometry, World Scientific, Singapore 2003.

[34] T. OURMIÈRES-BONAFOS, K. PANKRAShKIn, Discrete spectrum of interactions concentrated near conical surfaces, Appl. Anal. 97 (2018), 1628-1649.

[35] R.E. SchwARTZ, The five-electron case of Thomson's problem, Experim. Math. 22 (2013), 157-186.

[36] J.J. ThOMSON, On the structure of the atom: an investigation of the stability and periods of oscillation of a number of corpuscles arranged at equal intervals around the circumference of a circle; with application of the results to the theory of atomic structure, Phil. Mag. 7 (1904), 237-265. 